\title{
ON Net-based English Learning from Psycholinguistics Perspectives
}

\author{
Xianmin HUANG \\ Liuzhou Railway Vocational Technical College, Liuzhou, 545007, China \\ Email: hxm100@126.com
}

Keywords: Theory of Behaviorism, Theory of Structuralism, net-based English learning, analysis

\begin{abstract}
Internet is a magical world, many treasures can be found there. Internet is also an important tool in our work, study and daily lives. Compared with paper textbooks and encyclopedias, learning English online has become the best choice for its large amount of information and strong interactivity. What's more, it is scientific, advanced, intuitive, vivid, interesting and update soon. This thesis will apply Theory of Behaviorism and Theory of Structuralism to English podcasting, learning websites, BBS, radio on line and chatting -room in order to reinforce a positive cycle for the net-based English learners.
\end{abstract}

\section{Introduction}

English is one of the most widely spoken languages in the world. Learning English is very important as it keeps people at the right level with the changing world. It also enables them to understand the technological world and gives a chance to enjoy higher learning. Studying English can also give them a life-time career. But just as an old saying goes, learning English needs conditions, especially an English environment. With the development of integrating technology into language learning, many learning conditions and learning resources are available online. Podcasting is a way to receive audio/video files over the Internet. Learning websites provide a lot of information and materials, which can be easily downloaded. Distance education breaks out the geographical boundaries, many famous courses can be enjoyed even in remote areas. On learning English BBS, everyone can freely discuss and solve problems together. In English chat-rooms, speaking ability can be improved quickly and naturally. Internet brings the world towards us. It indeed has shortened the distance between people from the space and the time. This thesis will apply Theory of Behaviorism and Theory of Structuralism to English podcasting, English learning websites, internet languages and emoticons in order to reinforce the positive role of the net-based auxiliary for English learners.

\section{Net-based Media Provide Favorable Conditions for English Learners to Improve Their Consciousness}

According to an American psychologist J.B.Watson(1878 1858), learning is a process of creating conditional reflex, in which a kind of stimulus would take the place of another. By David $P$ Ausubel(1919 2008), another American psychologist, listening and reading comprehension process includes two stages---perception and cognition. Perception refers to aware the meaning of a potential material. If it is a written material, its form will be perceived, if it is an audio material, then its sound will become aware. Cognition is a phrase in which the previous perceived materials will get connected to the relevant information already existed in the cognitive structure (i.e. the memory of the brain) and then makes them understood.

Podcasting is a way to receive audio/video files over the Internet. The word 'podcasting' is created by MTV VJ Adam Curry in 2004, its video audio text together with some the fashionable elements, provides favorable conditions for foreign language learners to improve their consciousness. It will be helpful for training oral English in the "Bottom-up" approach and "Top-down" approach. What's more, it will enlarge the vocabulary in listening and reading practice. Podcasting lessons allow the learners to download the materials they want to read more than once, to go over them from audio instead of from a paper textbook, or to use as study assistance in general. They also allow the learners to pick up lessons they missed. On English podcasting, learning is a course of "stimulus - reflection" and "operant conditioning".

More and more learning websites are emerging over the years. Learning websites provide a lot 
of information and materials, which can be easily downloaded. Distance education breaks out the geographical boundaries, many famous courses can be enjoyed even in the remote areas. It is shown that college students who spent one or more hours in the English learning websites could achieve higher scores in English exams.

On learning English BBS, everyone can freely discuss and solve problems together.

Understanding native speakers and their accents is often one of the hardest parts of English learning. A great listening exercise is listening to English radio online. Radio hosts often speak quite fast which makes this exercise rather difficult; however, it will help to improve the listening skills and it is also an excellent way to pick up new words and learn about a variety of cultural topics.

Chatting on line, with native or with non-native English speakers, is an honorable way to practice in a stress-free and uninhibited environment. This is a particularly good method for a shy guy. It will help him to build confidence. People can share stories, loves, feelings and anything they want to talk about! It can help chatters to overcome communication barriers and make progress in communication.

These resources provide favorable conditions for English learners to improve their consciousness and enable them to practice English in a more inventive way rather than relying on books and classroom time.

\section{Findings and Recommendations}

A. Inter-languages' similarity plays a positive role in language acquisition

It is not a surprise to talk about the language transfer. In 1977, Kellerman put forward an important concept "Psychotypology", which means that the distance feeling about one's mother language and his target language will affect the language transfer. Most researchers focus on the inter-languages' difference and emphasizes its hindering role. They ignore its positive role. But Professor Ringbom from Åbo Akademi University revealed the complexity of language transfer phenomenon, using a newly unique perspective. From the learners' psychology, Professor Ringbom divided the similarity into perceived similarity and assumed similarity. In any kind of communication, foreign language learners would depend on his mother language. It is a popular belief that second language acquisition is strongly influenced by the learner's L1. The clearest support for this belief comes from "foreign" accents in the L2 speech of learners. When a Frenchman speaks English, his English sounds French. The learner's L1 also affects the other language levels - vocabulary and grammar. According to behaviourists, the process of learning a language is that of forming a kind of habits, thus the biggest obstacle of second language acquisition comes from previous knowledge, for language learners have formed certain kinds of habits when they are learning a second language. They would naturally transfer the skills learned in the L1 to the L2. In the case of similarities between the L1 and L2, language transfer functions positively, which would facilitate the L2 acquisition; while in the case of differences, it functions negatively, which makes it difficult to learn an L2, even causes errors. With the improvement of his foreign language level, this dependant will gradually become less and less.

According to Theory of Behaviorism (B. F. Skinner, Verbal Behavior 1957), the process of learning a language is to form a kind of habits. The biggest obstacle of second language acquisition comes from previous knowledge, for the language learners have formed certain kinds of habits when learning a second language. They would naturally transfer the skills in the L1 to the L2. In the case of similarities between the L1 and L2, language transfer functions positively, which would facilitate the L2 acquisition; while in the case of differences, it functions negatively, which makes it difficult to learn an L2, even causes errors.

According to Deller(2003), the mother tongue should be used as a resource to notice differences and similarities between the two languages; to let learners develop and produce their own materials, including their own tests; to encourage spontaneity and fluency; to have a beneficial effect on group dynamics and to receive ongoing and meaningful feedback from learners Owen (2003) said that it was useful to increase learner awareness, not only of grammar but also of the pragmatic and stylistic devices and their effects ${ }^{[1]}$.. In the process of English learning, the learners shouldn't only see the negative effects of their mother, they should also face up to the positive roles brought by the inter-languages' similarity. 
B. Network languages refract the learners' unique wisdom in word-reforming

With the increase in the network-mediated communication, network languages arise at the historic moment. They are abstract and vivid, far-fetched and too subtle to be described. They are lively, freely, kindly and humorous, particularly close to the life. They have certain social psychological bases. Through this language phenomenon, the corresponding psychological condition of the specific people in specific period can be seen.

The following dialogue is an excerpt from R U READY 2 TXT?

Viki: It's snowing quite strong outside be careful.

Sue: I will, thx.

Viki: $\quad$ wei, wei.....lei dim ar?

Sue: $\quad$ ok, la, juz got bk from Amsterdam loh, how $\mathrm{r} u$ ?

Viki: $\quad$ ok la. I have 9 tmrw.

Sue: $\quad$ haha, I have 2-4, sooooooooooo happy.

Viki: che... anyway...have your rash gone?

Sue: $\quad$ yes, but I have scar oh.....ho ugly ar.

Viki: icic.....ng gan yiu la.....still a pretty girl, haha!

It must be remembered that anyone reading this exchange is effectively eavesdropping on a private conversation, with all the in-jokes, understatements and privately coded references that would be expected in unrehearsed speech. Hence the exchange - I have 9 tmrw; haha, I have 2-4 refers to the next day's lecture timings, and automatically explains why Sue is "sooooooooooo happy". It is interesting to note at this point how closely text English indicates the intonation of Sue's statement.

Other utterances - "wei, wei.....lei dim ar?" - remain utterly opaque, until it is explained that Viki and Sue are actually Chinese students attending courses in England, and so "ng gan yiu la" is texted Cantonese for "it doesn't matter." [2]

Here, Viki and Sue's unconventional and rebellious character come up from the paper. They harvest their joy and relaxation by this kind of out-of- line expression. Network languages can develop the learners' interest in reading, improving their writing ability.

Usually, Network languages involve homophonic words, metaphor, abbreviation, transliteration, description, decomposition, synthesis and mix. In order to meet the needs of human social activities, such as political, economical, culture, language is a bridge of communication. It is also an important symbol of national culture. Various kinds of net languages are born. People have different opinions for the net languages used on net. To this phenomenon, some people say it will lose traditional culture and will decrease people's common interests. The society will be more chaotic. Others say they are keeping pace with The Times. The emergence of network context promotes the language growth and its popularity. They show entertainment, fast food, innovation, fashion and comprehensive cultural connotation.

C. Emoticons show the great figure-imagination and word-creation

An emoticon is a textual portrayal of a writer's mood or facial expression. Emoticons are very popular on net. Here are some examples: : -) is a very common smiling face, usually used at the end of a sentence or a passage; :-[ is frown; :-/ or :- $\backslash$ is skepticism, annoyance, or a slight frown; $\wedge_{-} \wedge$ is a gentle and polite smile; and then ${ }^{\wedge} .^{\wedge}$ is naturally an implicit and elegant smile; T-T is a double long stream of tears on a crying face; $\wedge^{\wedge} 0^{\wedge}$ is a surprise; ${ }^{\wedge} \iota^{\wedge}$ is a praise; $:-\mid$ is often used with a contrasting statement to convey biting sarcasm (e.g. "That was hilarious! :-|") ; :-x is a sealed lips; used to convey "I shouldn't have said that" or sometimes shocked silence.

Emoticons are popular. They are very vivid and fun. Some people like to use them to get through an e-mail or chat. Such simply paintings tend to convey more information than words. In this high pressure society, people are yearning for their cheerful and freely childhood life. They add lovely feeling and character to cold digital communications. This kind of humorous language is a gentle blow to the modern boring life.

All the expressions in the network languages can be stated with traditional way. But net users still like to rack their brains to create these network languages. Why? According to a psychologist, stress is a natural part of everyday life and there is no way to avoid it. Stress contributes to one's mental decline and hence endangers his health. Relaxation, the opposite of stress, is essential for a healthy mind and body. People need a way to understand each other and communicate with each 
other. At this very time the network is becoming a good way to express their feelings for the net is tending to elude capture and perception, egos can easily displayed which usually has little chance to show off in real life.

\section{Conclusion}

Science and technology act as a two-sided sword: there are always advantages and disadvantages presenting at the same time. It is essential to know both the advantages and the disadvantages. On one hand, net-based English learning is very different from regular classroom learning. Sufficient self-discipline, time-management and self-teaching skills must be required by the learners with their online learning. Without self-discipline, the learners would just do nothing or delay something because of his laziness. Without time-management skills, it is impossible for the learners to get anything. They would suffer both physically and emotionally with the loss of confidence and control of time. And without self-teaching skills, some course materials wouldn't make any sense anymore. Basically, teacher's instructions are needed from time to time, and if there is no teachers presenting to help them out, they would not be able to learn anything. On the other hand, most net users are highly educated and quality, under the age of 35 . They have active thinking and they represent the latest trends. Net-based English learning can make up for the inadequacy of the traditional English learning methods. As for the learners' cognitive style, attitude and emotion, the positive roles created by the learning environment through the network are not to be ignored. When linking up the inherent relations among the emotional factors, cognitive factors and net-based auxiliary, the learners will show more interests in English learning, their self-confidence is improved, which is the most important thing. Then they are more willing to take part in the practice they need to improve listening, speaking, reading and writing skills. As they continue to make progress, they will feel more confident and more willing to seek out learning opportunities, thus reinforcing a positive cycle.

\section{Notes}

[1] Jarek Krajka, YOUR MOTHER TONGUE DOES MATTER! TRANSLATION IN THE CLASSROOM AND ON THE WEB [1], from Owen (2003)2004, Teaching English with Technology---A Journal for Teachers of English, IATEFL, Poland Computer Special Interest Group, 2004

[2] Neil McBeath, R U READY 2 TXT? (Technical Studies Institute Neil McBeath, 2006),

Teaching English with Technology---A Journal for Teachers of English, IATEFL, Poland Computer Special Interest Group, 2006

\section{References}

[1] Galina Kavaliauskienè, PODCASTING: A TOOL FOR IMPROVING LISTENING SKILLS, Teaching English with Technology---A Journal for Teachers of English, IATEFL, Poland Computer Special Interest Group, 2008

[2] Marta Navarro-Coy and Carlos Periñán-Pascual, LANGUAGEQUESTS IN AN OFF-LINE COURSE MANAGEMENT SYSTEM 2008

[3] Andrzej Zychla, PODCAST YOURSELF! Teaching English with Technology---A Journal for Teachers of English, IATEFL, Poland Computer Special Interest Group, 2007

[4] Hanaa Khamis, Decision-making Tasks in Computer-mediated Communication (CMC) Teaching English with Technology---A Journal for Teachers of English, IATEFL, Poland Computer Special Interest Group, 2009

[5] Zonglun CHEN, Theoretical Research of Comprehensive English Teaching, Journal of Anhui University of Technology(Social Sciences), 2006.05.

[6] Xianmin HUANG, Analysis on Computer-assisted English Teaching from the Perspective of Psycholinguistics, Journal of Changchun University of Science and Technology,2010.01. 